\title{
Evolución y perdurabilidad de empresas bursátiles de la bolsa mexicana de valores de 1895-2016
}

\author{
Salvador Arturo Galicia Anaya* \\ Luis Arturo Rivas Tovar ${ }^{\star *}$ \\ Magali Cárdenas Tapia***
}

Fecha de recibido: 14 de junio de 2019 Fecha de aprobado: 20 de septiembre de 2019

Para citar: Galicia Anaya, S. A., Rivas Tovar, L. A. \& Cárdenas Tapia, M. (2020). Evolución y perdurabilidad de empresas bursátiles de la bolsa mexicana de valores de 1895-2016. Universidad \& Empresa, 22(38), 183-210. https://doi.org/10.12804/revistas. urosario.edu.co/empresa/a.8003

* Doctor en Ciencias Administrativas, ESCA, Sto. Tomás, IPN (México). Catedrático de la EBC, Correo electrónico: sgalicia6166@ hotmail.com

** Doctor en Ciencias Administrativas, ESCA, Sto. Tomás, IPN (México). Doctor en estudios europeos, Instituto Ortega y Gasset, España. Catedrático IPN - ESCA, Sto. Tomás, Ciudad de México. Miembro del Sistema Nacional de Investigadores Nivel II. Correo electrónico: larivas33@hotmail.com

*** Doctora en Ciencias de la Administración UnAm (México). Catedrática IPN - ESCA, Tepepan-México. Miembro del Sistema Nacional de Investigadores Nivel Candidato. Coordinadora Red de Expertos en Sistemas Complejos del IPN Correo electrónico: mcardenast@ipn.mx 


\section{Resumen}

El objetivo de la investigación fue analizar la evolución y perdurabilidad de empresas bursátiles de la Bolsa Mexicana de Valores (BMv) de 1895 a 2016. El método de investigación fue un análisis histórico-descriptivo de 1663 empresas que cotizaron un año o más dentro de ese periodo. Se concluye que el 51.53\% de empresas dejan de ser bursátiles en los primeros cinco años. Utilizando la Teoría de Redes, y dos variables de centralidad estructural: grado nodal (nodal degree) y cercanía (closeness centrality), se evaluó la muestra de 91 empresas con 21 años o más de perdurabilidad en Bmv; concluyendo que, 5.47\% perduró durante ese periodo.

Los resultados del análisis muestran que los periodos presidenciales con mayor participación bursátil fueron: Porfiriato, Desarrollo estabilizador (López Mateos-Díaz Ordaz) y Neoliberalismo priista, (Salinas-Zedillo). Las variables de centralidad estructural demuestran que el sector industrial fue el de mayor perdurabilidad y el sector servicios el de mayor volatilidad en la BMv, existiendo correlación entre variables de grado nodal y cercanía: A mayor número años de empresas activas en la Bmv, mayor cercanía empresarial existía con el presidente en turno. La relevancia de la investigación es ser el primer trabajo que analiza la perdurabilidad de empresas bursátiles en 121 años, mediante el análisis de redes.

Palabras clave: perdurabilidad, bolsa mexicana de valores, empresas bursátiles, sectores económicos, Teoría de Redes.

\section{Evolution and Perdurability of Stock Companies of the Mexican Stock Exchange of 1895-2016}

\section{Abstract}

The objective of the research was to analyze the evolution and perdurability of stock companies of the Mexican Stock Exchange (MSE) from 1895 to 2016. The research method was a historical-descriptive analysis of 1663 companies quoting a year or more within the period, concluding: $51.53 \%$ of companies stop being stock in the first five years. Using the theory of networks, with two variables of structural centrality: nodal degree and closeness (centrality), the sample of 91 companies with 21 years or more of perdurability in MSE was evaluated; concluding that, $5.47 \%$ lasted during the period.

The results of the analysis conclude that the presidential periods with the highest market share were the ones of Porfiriato Stabilizing development (Lopez Mateos-Díaz Ordaz) and PRI neoliberalism (Salinas-Zedillo). The centrality structural variables show the industrial sector was the one with greater perdurability, and the service sector the one with greater volatility in the mSE. There is a correlation between the variables of nodal degree and proximity: to a greater number of years of active companies in the MSE, a greater proximity business had with the president in turn. The relevance of the research is to be the first work that analyzes the perdurability of stock companies, through the analysis of networks in 121 years.

Keywords: Perdurability, Mexican stock exchange, stock companies, economic sectors, theory of networks.

\section{Evolução e perdurabilidade de empresas bolsistas da bolsa mexicana de valores de 1895-2016}

\section{Resumo}

O objetivo desta pesquisa foi analisar a evolução e perdurabilida de de empresas bolsistas da Bolsa Mexicana de Valores (Bмv) de 1895 a 2016. O método de pesquisa foi uma análise histórica-descritiva de 1663 empresas que cotizaram um ano ou mais dentro do período, concluindo: $51.53 \%$ de empresas deixam de ser bolsistas nos primeiros cinco anos. Utilizando a Teoria de Redes, e duas variáveis de centralidade estrutural: grau nodal (nodal degree) e proximidade (closeness centrality), se avaliou a amostra de 91 empresas com 21 anos ou mais de perdurabilidade em $\mathrm{BMV}$; concluindo que, $5.47 \%$ perdurou durante esse período. 
Os resultados da análise concluem: os períodos presidenciais com maior participação bolsista foram: Porfiriato, Desenvolvimento estabilizador (López Mateos-Díaz Ordaz) e Neoliberalismo PRI, (Salinas-Zedillo). As variáveis de centralidade estrutural, demostram: setor industrial foi o de maior perdurabilidade e setor serviços o de maior volatilidade na BMv, existindo correlação entre variáveis de grau nodal e proximidade: a maior número de anos de empresas ativas na BMv, maior proximidade empresarial existia com o presidente em turno. A relevância da pesquisa é ser o primeiro trabalho que analisa a perdurabilidade de empresas bolsistas em 121 anos, mediante a análise de redes.

Palavras-chave: perdurabilidade, bolsa mexicana de valores, empresas bolsistas, setores econômicos, Teoria de Redes.

\section{Introducción}

La Bolsa Mexicana de Valores se fundó en 1895 en el periodo del presidente Porfirio Díaz, iniciando con empresas del sector primario, principalmente empresas mineras, dado el énfasis en la extracción de minerales, el cual fue el más preponderante de las empresas al concentrar en los gobiernos coloniales su atención de metales preciosos desde finales del siglo xviII y principios del xix (Bolsa Mexicana de Valores, 1994).

La economía nacional, después de las guerras de Reforma, continúo enfocándose en el sector minero. Es decir, durante el periodo presidencial conocido como la dictadura de Porfirio Díaz (1876-1911), fueron los años en que mayor número de empresas mineras que históricamente hubo registradas en la Bмv.

Durante el Porfiriato, las empresas del sector minero estaban incorporadas en la вмv, representando el $62.88 \%$ del total de todas las empresas que iniciaron operaciones en la BMv, en cambio en el sector secundario o industrial tan solo tenía el $22.27 \%$, y el $14.85 \%$ se concentraban en empresas del sector servicios. Por eso, es importante revisar el momento histórico por el que pasaba el país y su economía, para comprender la razón que imperaba y entender los cimientos económicos del país. Tal y como se muestra en la tabla 4.

El objetivo de esta investigación fue analizar la evolución y perdurabilidad de las empresas que cotizaron en la Bolsa Mexicana de Valores, durante 121 años en el periodo de 1895 a 2016, describiendo la evolución y características de las empresas de acuerdo con el sector económico al que pertenecen, haciendo un análisis histórico de los acontecimientos 
políticos y económicos del país, considerando 22 periodos presidenciales registrados en el tiempo analizado.

El método de investigación inició con un análisis histórico-descriptivo de 1663 empresas que cotizaron activamente por lo menos durante un año en el periodo de 1895 a 2016. Para efecto de comprobar la perdurabilidad de las empresas, se realizó adicionalmente un análisis utilizando la Teoría de Redes de 91 empresas que cotizaron por más de 21 años, mediante dos variables de centralidad estructural: grado (degree) y cercanía (closseness centrality), para llevar a cabo el análisis de los datos se utilizó el software acceso libre CYTOSCAPE (versión 3.2.0.).

El trabajo aporta un análisis histórico sobre el comportamiento de las empresas que cotizaron en la BMv en un periodo de 121 años de 1895 a 2016 y cómo han evolucionado cada uno de los sectores económicos, así como los periodos políticos en los que han participado mayor número de empresas. Por otra parte, el análisis de la perdurabilidad de las empresas en la BMv, utilizando la Teoría de Redes, no se ha reportado en la literatura, por lo que resulta un enfoque innovador.

Durante la revisión no se encontraron trabajos que estudiaran la evolución de la BMv y tampoco la perdurabilidad de las empresas y mucho menos durante un periodo de 121 años, así que el presente trabajo será el primero en estudiar la perdurabilidad de las empresas, así como la evolución de los sectores económicos en el periodo de 1895 a 2016 y, por otra parte, se realizó también el análisis de la perdurabilidad de las empresas con más de 21 años de cotizar en la Bmv por medio de la teoría de redes.

Este artículo se estructuró en cuatro apartados: el primero presenta la revisión de la literatura sobre investigaciones realizadas en la bolsa de valores de México y el mundo; en el segundo se presenta el diseño metodológico de la investigación, incluyendo la definición de las dos variables de centralidad estructural utilizadas en la investigación; en el tercero se revelan los resultados del análisis de la perdurabilidad de las empresas en la BMv y la discusión de resultados; en el cuarto se presentan las conclusiones. 


\section{Revisión de literatura}

Esta sección hace referencia al contexto de la BMv y a las bolsas de valores en el mundo, a los periodos políticos de México y a los periodos presidenciales considerados, así como a los conceptos sobre la Teoría de Redes y las variables de centralidad estructural.

\subsection{Bolsa Mexicana de Valores}

El estudio de la evolución de las bolsas de valores ha recibido la atención de diversos científicos, la mayor parte de los trabajos hacen énfasis en las utilidades que generan las bolsas y pretenden predecir patrones de inversión exitosos.

En el caso de la BMv, se destacan estudios acerca de su evolución. San Martin-Reyna y Duran-Escalada (2012) concluyeron que las empresas familiares mexicanas adoptan estructuras de gobierno corporativo sustancialmente diferentes para las empresas no familiares, lo cual impacta en el desempeño de la empresa.

Por otra parte, Moreno-Lázaro (2015), en el trabajo más panorámico que se ha encontrado, examinó la historia de la Bmv desde el final de la Revolución hasta 1975, concluyendo que la bolsa no cumplió su labor en el financiamiento corporativo, sino que más bien fue instrumento económico y político del gobierno. San Martín, Durán y Durán (2017) destacan que la mayoría de las empresas que cotizan en la BMv son empresas líderes, que suelen ser las empresas más representativas de los diferentes sectores de la economía nacional.

En otra investigación, Islas (2017) menciona que han existido grandes empresas bursátiles que han sido privadas o inclusive estatales, algunas de ellas con perfiles de monopolio. Sin embargo, a partir del siglo $\mathrm{xx}$, se inicia un ciclo de adquisición y fusión de distintas empresas, de tal forma que han llegado a crear conglomerados como el Grupo México, que surgió en el sector constructor y se ha transformado en una sola empresa, que ha llegado a vincular diversas a organizaciones en distintas zonas a nivel nacional y sobre todo perteneciendo a distintos sectores de la economía mexicana.

Montes (2017), por su parte, destaca el papel que tiene los aspectos fiscales que derivan de determinados registros en las inversiones bursátiles y su repercusión fiscal a las compañías, lo cual ha sido una de las barreras que han favorecido las fusiones y adquisiciones. 
Chamorro, Domínguez y García (2017) aportan evidencia de que el número de empresas listadas en la BMv ha disminuido, debido a que el financiamiento que ofrece el mercado de capitales constituye una barrera de ingreso a empresas Pymes, las cuales suelen tener problemas de formalización que imponen la visibilidad pública de la empresa que cotizan en la BMv, limitando con esto el crecimiento del mercado bursátil en México.

\subsection{Bolsa de valores en el mundo}

Existen diversos estudios sobre las bolsas de valores en el mundo Wang, Xie y Stanley (2018) encontraron que utilizando índices de precios diarios de 57 mercados bursátiles de 2005 a 2014, hay una alta correlación ente los mercados de las bolsas y que los mercados de EE.uu., Alemania y Japón claramente sirven como "Hubs" o conectores en las bolsas mundiales.

Ren y Zhou (2014), al estudiar en la bolsa China de Shanghái el retorno de 367 acciones "A" negociadas desde el 4 de enero de 1999 hasta el 30 de diciembre de 2011, concluyeron que había evolución dinámica en sectores empresariales como Tecnologías de la Información (TI), electrónica y el mercado inmobiliario.

Después de analizar a 32 emisores de las categorías i y il de la Bolsa de Bucarest, Rumania, pertenecientes a nueve sectores económicos, para el periodo 2010-2012, identificaron posibles firmas potenciales en bancarrota, pero que aún no han quebrado, lo cual ayuda a los inversores a tomar decisiones apropiadas en el mercado bursátil.

Neal y Davis (2006), al hacer un estudio retrospectivo de la Bolsa de Londres encontraron que, en 1914, la Bolsa de Londres cotizaba y negociaba un tercio del capital público disponible para los inversores en cualquier parte del mundo. Las razones de este éxito consistían en que los propietarios del intercambio, al aumentar el número de usuarios, incrementaban también los ingresos de una manera constante, la razón consistía en favorecer innovaciones financieras. Cuando las innovaciones cesaron la bolsa perdió su preeminencia mundial.

Wang, Xie y Chen (2017), al estudiar las acciones en el mercado estadounidense mediante el análisis de redes complejas en varios horizontes de tiempo, encontraron que las estructuras y propiedades topológicas de las redes varían a lo largo del tiempo, además 
que existe un efecto de agrupamiento sectorial en las redes en escalas de tiempo pequeñas $\mathrm{y}$, por último, que solo una parte de las conexiones en las redes resulta perdurable en el tiempo.

\subsection{Teoría de Redes}

En la tabla 1 se presentan las variables de centralidad estructural utilizadas en la investigación para analizar a las empresas con más de 20 años de cotizar en las BMv de 1895 a 2016, utilizando la Teoría de Redes.

Tabla 1. Variables de centralidad estructural

\begin{tabular}{|c|c|c|}
\hline Variables & Explicación & Interpretación \\
\hline $\begin{array}{l}\text { Grado } \\
\text { (degree) }\end{array}$ & $\begin{array}{l}\text { En las redes no dirigidas, el grado del nodo n es } \\
\text { el número de aristas con enlaces a } n \text {. }\end{array}$ & $\begin{array}{l}\text { El grado se define como el número de otros actores } \\
\text { a los cuales un actor está directamente unido o es } \\
\text { adyacente, la variable grado organiza a los actores } \\
\text { por el número efectivo de sus relaciones directas en el } \\
\text { conjunto de la red. Esta medida trata de la centralidad } \\
\text { local de un actor con respecto a los actores cercanos. }\end{array}$ \\
\hline $\begin{array}{l}\text { Cercanía } \\
\text { (closenness } \\
\text { centrality) }\end{array}$ & $\begin{array}{l}\text { La cercanía de un nodo se calcula } \\
\text { C(i)=(n-1)/Di+ } \\
\text { donde Di+ } \\
\text { es la suma de las distancias desde i a todos los } \\
\text { demás puntos, que puede ser representado co- } \\
\text { mo la suma de las filas i de la matriz de distancias }\end{array}$ & $\begin{array}{l}\text { La cercanía representa la independencia, la capaci- } \\
\text { dad de llegar a muchos de los otros miembros de la } \\
\text { red directamente, sin apoyarse en intermediarios, } \\
\text { esto es, es el número de pasos que por medio de } \\
\text { la red deben dar para relacionarse con el resto. El } \\
\text { índice es mayor cuando aumenta la cercanía }\end{array}$ \\
\hline
\end{tabular}

Fuente: elaboración propia con base en Sanz (2003), Freeman (2000), Newman (2003).

\section{Metodología}

El método utilizado fue de dos tipos: un análisis descriptivo de un total 1663 empresas que cotizaron en la BMv, por lo menos durante un año, dentro del periodo de 1895 a 2016. La información se organizó en tres etapas: 1) por sector económico, 2) por eventos históricos relevantes en México; es decir, por periodo presidencial y 3) por la perdurabilidad de las empresas en la BMv. La recopilación de datos se obtuvo del centro de información de la BMv, la mayor parte de esta información está en papel contenida en cajas y se requiere un permiso especial para acceder a ellas, ya que no existe información en medios electrónicos. 


\subsection{Primera fase: sectores económicos}

Para efectos de la presente investigación, se consideraron tres sectores económicos, de acuerdo con el Instituto Nacional de Estadística y Geografía INEGI (2013). El sector primario se clasifica en subsectores tales como: el de agricultura, minería y todas aquellas empresas o industrias de recursos naturales; el sector secundario, o también conocido como industrial, es en el que se encuentran las empresas dedicadas a la fabricación, ingeniería y construcción principalmente y, por último, el sector terciario, encontrándose principalmente las empresas de servicios.

\subsection{Segunda fase: procesos políticos y económicos de México por presidente}

La tabla 2 muestra, después del análisis que se llevó a cabo, cómo se han conformado los procesos políticos y económicos de México por presidentes en 121 años de revisión.

Tabla 2. Revisión de los procesos políticos y económicos de México por presidente

\begin{tabular}{|c|c|}
\hline Fases históricas & Presidentes \\
\hline Porfiriato (1876-1911) & Porfirio Díaz (1895-1911) \\
\hline \multirow{3}{*}{$\begin{array}{l}\text { Periodo Revolucionario } \\
\text { (1911-1924) }\end{array}$} & Francisco I. Madero (1911-1913) \\
\hline & Venustiano Carranza (1914-1920) \\
\hline & Álvaro Obregón (1920-1924) \\
\hline \multirow{4}{*}{$\begin{array}{l}\text { Maximato } \\
(1924-1934)\end{array}$} & Plutarco Elías Calles (1924-1928) \\
\hline & Emilio Portes Gil (1928-1929) \\
\hline & Pascual Ortiz Rubio (1930-1931) \\
\hline & Abelardo L. Rodríguez (1932-1933) \\
\hline \multirow{6}{*}{$\begin{array}{l}\text { Desarrollo Estabilizador } \\
\text { (1934-1970) }\end{array}$} & Lázaro Cárdenas del Río (1934-1940) \\
\hline & Manuel Ávila Camacho (1940-1946) \\
\hline & Miguel Alemán Valdés (1946-1952) \\
\hline & Adolfo Ruiz Cortines (1952-1958) \\
\hline & Adolfo López Mateos (1958-1964) \\
\hline & Gustavo Díaz Ordaz (1964-1970) \\
\hline \multirow{2}{*}{$\begin{array}{l}\text { Populismo } \\
(1979-1982)\end{array}$} & Luis Echeverría Álvarez (1970-1976) \\
\hline & José López Portillo (1976-1982) \\
\hline \multirow{3}{*}{$\begin{array}{l}\text { Neoliberalismo Priista } \\
\text { fase I } \\
(1982-2000)\end{array}$} & Miguel de la Madrid Hurtado (1982-1988) \\
\hline & Carlos Salinas de Gortari (1988-1994) \\
\hline & Ernesto Zedillo Ponce de León (1994-2000) \\
\hline \multirow{2}{*}{$\begin{array}{l}\text { Neoliberalismo Panista } \\
(2000-2012)\end{array}$} & Vicente Fox Quesada (2000-2006) \\
\hline & Felipe Calderón Hinojosa (2006-2012) \\
\hline
\end{tabular}




\begin{tabular}{ll}
\hline \multicolumn{1}{c}{ Fases históricas } & \multicolumn{1}{c}{ Presidentes } \\
\hline Neoliberalismo Priista & Enrique Peña Nieto (2012-2016) \\
fase ॥ & \\
$(2012-2016)$ & \\
\hline
\end{tabular}

Fuente: elaboración propia.

Como parte del análisis realizado se puede determinar que, en la historia de la bolsa se han dividido en ocho fases históricas los procesos políticos y económicos por los que atravesó el país en los 121 años de existencia de la BMv de 1895 a 2016.

\subsection{Tercera fase: empresas bursátiles con mayor perdurabilidad en la BMV}

En la tercera etapa, se seleccionaron 91 empresas que cotizaron en la bmv por más de 21 años desde 1895 a 2016, validando así la perdurabilidad; en esta etapa se utilizó la Teoría de Redes complejas, se utilizaron dos variables de centralidad estructural: grado (degree) y cercanía (closeness centrality).

Para el análisis de la información, se utilizó el software de acceso libre CYTOSCAPE (versión 3.2.0.) basado en la Teoría de Redes expuesta por Cárdenas, Rivas, Ramírez y Simón (2015), lo cual permitió visualizar las redes por medio de grafos por sector económico y por periodo presidencial, así como su evolución y comportamiento en la BMv desde el año de 1895 hasta diciembre de 2016. El software proporciona índices que permiten analizar la perdurabilidad de las empresas bursatiles.

\section{Resultados}

Los resultados de la investigación se presentan de acuerdo con el análisis de la información mencionada en la metodología de la investigación: por sectores económicos, fases históricas, periodos presidenciales, perdurabilidad de las empresas y el análisis con la Teoría de Redes. 


\subsection{Sectores económicos}

A continuación, se muestran los principales resultados que arrojó el análisis de perdurabilidad de las 1663 empresas que cotizaron en la Bмv, por lo menos durante un año, en el periodo de 1895 a 2016 de los tres sectores económicos.

Tabla 3. Empresas que cotizaron en la bmv de 1895 a 2016 por sector económico

\begin{tabular}{ccc}
\hline Sector Económico & No. de empresas & $\%$ \\
\hline Sector primario o Minero & 285 & 17.14 \\
\hline Sector secundario o Industrial & 588 & 35.36 \\
\hline Sector terciario o Servicios & 790 & 47.50 \\
\hline Total & 1663 & 100.00
\end{tabular}

Fuente: elaboración propia con base en BMv (2016).

La tabla 3 muestra como resultado del análisis de las 1663 bursátiles en la BMV, la perdurabilidad acumulada por sector económico durante 121 años, pudiéndose observar que, en primer lugar, se encuentran las empresas del sector servicios con $47.50 \%$, el segundo lugar lo ocupan las empresas del sector industrial con $35.36 \%$ y, por último, las empresas mineras con $17.14 \%$ del total.

\subsection{Fases históricas y periodos presidenciales}

La historia de la bolsa se ha dividido en ocho fases históricas de acuerdo con los procesos políticos y económicos por los que atravesó el país en los 121 años de existencia de la BMv de 1895 a 2016, la primera fue la Dictadura de Porfirio Díaz de 1876-1911, la segunda fue el periodo revolucionario 1911-1924, en tercer lugar el Maximato conformado de 1924-1934, la cuarta fase fue el Desarrollo Estabilizador de 1934-1970, en quinto lugar se encuentra el Populismo de 1970-1982, la sexta fue la conocida como Neoliberalismo Priista fase I comprendida de 1982-2000, la séptima fue el Neoliberalismo panista de 2000- 2012 y, finalmente, la octava fue el Neoliberalismo Priista fase II de 2012-2016 (fecha en que se cerró el análisis de la información que se evaluó, para fines del estudio).

En las siguientes tres tablas, se presenta la información de empresas bursátiles en BMv, de 1895 a 2016 : 
Tabla 4. Empresas por sector económico, fases históricas y periodo presidencial

\begin{tabular}{|c|c|c|c|c|c|c|c|c|}
\hline & $\begin{array}{c}\text { Porfiriato } \\
\text { 1876-1911 } \\
\text { Díaz }\end{array}$ & \multicolumn{3}{|c|}{$\begin{array}{c}\text { Periodo Revolucionario } \\
1911-1924\end{array}$} & \multicolumn{4}{|c|}{ Maximato 1924 -1934 } \\
\hline & $\begin{array}{c}\text { Díaz } \\
\text { 1876- } \\
1911\end{array}$ & $\begin{array}{c}\text { Madero } \\
1911- \\
1913\end{array}$ & $\begin{array}{c}\text { Carranza } \\
1914- \\
1920\end{array}$ & $\begin{array}{c}\text { Obregón } \\
\text { 1920- } \\
1924\end{array}$ & $\begin{array}{l}\text { Calles } \\
1924- \\
1928\end{array}$ & $\begin{array}{c}\text { Portes Gil } \\
1928- \\
1929\end{array}$ & $\begin{array}{c}\text { Ortiz } \\
\text { Rubio } \\
1930- \\
1931\end{array}$ & $\begin{array}{c}\text { Abelardo } \\
\text { Rodríguez } \\
1932- \\
1933\end{array}$ \\
\hline Minero & 271 & 41 & 49 & 23 & 21 & 10 & 6 & 22 \\
\hline Industrial & 96 & 13 & 37 & 12 & 8 & 7 & 4 & 7 \\
\hline Servicios & 64 & 11 & 11 & 6 & 7 & 7 & 3 & 3 \\
\hline Total & 431 & 68 & 97 & 41 & 36 & 24 & 13 & 32 \\
\hline
\end{tabular}

Fuente: elaboración propia, basada en los reportes bursátiles anuales de la BMV.

En la tabla 4 se puede observar que durante los 30 años que duró la dictadura de Porfirio Díaz, ${ }^{1}$ las empresas con mayor participación fueron las del sector primario, principalmente empresas mineras, fundamentalmente porque se visualizó con grandes esperanzas de crecimiento para un país que, en ese momento, contaba con un alto índice de pobreza. Además, en esa época los funcionarios responsables empezaron a descubrir que México se encontraba encima de unos grandiosos yacimientos mineros en varias de sus regiones, por lo que el Presidente Porfirio Díaz otorgó apoyos y concesiones principalmente a las empresas extranjeras, por ser estas las que en ese momento tenían mayor capacidad financiera, lo cual traería bonanza a la economía mexicana.

Durante el periodo revolucionario hubo una salida considerable de las empresas de la BMv, explica Paz (2006) que durante este periodo se asientan cuatro aspectos fundamentales para el futuro económico de México: 1) cambios importantes en las estructuras de la sociedad, 2) importante transformación política, 3) se establecen nuevas pautas enfocadas en el desarrollo del país y 4) se dan grandes cambios revolucionarios para crear una transformación económica para el futuro del país.

Moya (2007) expone que en diciembre de 1876 Porfirio Díaz da inicio al periodo conocido en la historia como el "Porfiriato". Posteriormente, después de los festejos por el centenario de México, en diciembre de 1910, Porfirio Díaz inicia otro nuevo periodo presidencial. Sin embargo, en el verano de 1911, este periodo es interrumpido, dando por concluido su último mandato. Para efectos del estudio, se considera el periodo de Porfirio Díaz de 1895 (año en que se funda la BMv) a 1911. 
Durante el Maximato ${ }^{2}$ se inició la reconstrucción del país, con el gobierno del presidente Plutarco Elías Calles, el cual influyó en los tres presidentes siguientes, razón por la cual a ese periodo se le ha llamado Maximato por Plutarco Elías Calles apodado 'Jefe Máximo de la revolución'.

A continuación, en la tabla 4a se muestra como las fases históricas y los aspectos más relevantes que se dieron durante la etapa conocida en México como Desarrollo Estabilizador (1934-1970)

Tabla 4a. Empresas por sector económico, fases históricas y periodo presidencial

\begin{tabular}{lcccccc}
\hline \multicolumn{7}{c}{ Desarrollo Estabilizador 1934-1970 } \\
\hline & $\begin{array}{c}\text { Cárdenas } \\
1934-1940\end{array}$ & $\begin{array}{c}\text { Ávila C. } \\
1940-1946\end{array}$ & $\begin{array}{c}\text { Alemán } \\
1946-1952\end{array}$ & $\begin{array}{c}\text { Ruiz } \\
1952-1958\end{array}$ & $\begin{array}{c}\text { López M. } \\
1958-1964\end{array}$ & $\begin{array}{c}\text { Díaz Ordaz } \\
1964-1970\end{array}$ \\
\hline Minero & 21 & 12 & 7 & 5 & 12 & 9 \\
\hline Industrial & 14 & 28 & 37 & 67 & 187 & 167 \\
\hline Servicios & 9 & 24 & 20 & 18 & 250 & 224 \\
\hline Total & 44 & 64 & 64 & 90 & 449 & 400 \\
\hline
\end{tabular}

Fuente: elaboración propia, basada en los reportes bursátiles anuales de la BMV.

En la tabla 4a se presenta el periodo del Desarrollo Estabilizador ${ }^{3}$ de 1934 a 1970, el cual inicia con el gobierno de Lázaro Cárdenas quien se enfocó al desarrollo económico y social del país, posteriormente el sexenio de Miguel Alemán es considerado como el inicio de la industrialización del país, aunque en realidad fue durante el sexenio de Ávila Camacho 1940-1946 como inicia el "Modelo de Industrialización Sustitutiva" o "Modelo de Sustitución de Importaciones”.

[...] se crearon algunos organismos con este fin como: Sosa Texcoco, S.A. (1940); el ImSS (1942); Altos Hornos de México, S.A. (1942); Cobre de México, S.A. (1943); Guanos

2 Como expone Ramírez (2013), el periodo conocido como Maximato (1924-1934), denominado así por el apodo de Plutarco Elías Calles, 'Jefe Máximo de la revolución', aunque el periodo presidencial de Plutarco Elías Calles fue (1924-1928), continuó con las políticas de reconstrucción nacional e institucionalización de la vida política del país hasta 1934, aún sin ser presidente, tuvo una fuerte influencia sobre Emilio Portes Gil, Pascual Ortiz y Abelardo Rodríguez.

3 Como menciona Colegio de México (2003), durante el sexenio de Lázaro Cárdenas (1934-1940) su administración se enfocó en los rubros del gasto para fomentar el desarrollo económico y social, poniendo especial atención a los gastos administrativos del gobierno, realizando grandes obras de infraestructura en el sector agrícola. El crecimiento industrial fue el objetivo en su política económica, alcanzando un crecimiento de la economía mexicana por medio del desarrollo económico y urbano. También se apoyó al sector financiero y productivo por medio de políticas macroeconómicas del gobierno, generando un importante flujo de nuevos capitales del exterior y con mayores márgenes de ahorro. 
y Fertilizantes de México, S.A. (1943); y, se reorganizó NAFIN (Nacional Financiera) con el propósito de revitalizar el aparato productivo del Estado y beneficiar a la iniciativa privada del país (Lara, 2013).

En el sexenio de Adolfo Ruiz Cortines se incrementó el número empresas que cotizaban en la BMv. La estabilidad económica y política durante los sexenios de Adolfo López Mateos y Gustavo Díaz Ordaz favorecieron una espectacular multiplicación de las empresas, pudiendo apreciar así que, son los sexenios de López Mateos y Díaz Ordaz son los que registran mayor número de empresas cotizando en la BMv.

Finalmente, la tabla $4 \mathrm{~b}$ muestra el análisis de cuatro fases históricas y por periodo presidencial, así como los aspectos más relevantes que se dieron durante la etapa conocida en México como Populismo (1970-1982), Neoliberalismo Priista Fase i (1982-2000), Neoliberalismo Panista (2000-2012) y Neoliberalismo Priista Fase II (2012-2016).

Tabla 4b. Empresas por sector económico, fases históricas y periodo presidencial

\begin{tabular}{|c|c|c|c|c|c|c|c|c|}
\hline & \multicolumn{2}{|c|}{$\begin{array}{l}\text { Populismo } \\
1970-1982\end{array}$} & \multicolumn{3}{|c|}{$\begin{array}{c}\text { Neoliberalismo Priista } \\
\text { fase I } \\
1982-2000\end{array}$} & \multicolumn{2}{|c|}{$\begin{array}{c}\text { Neoliberalismo } \\
\text { Panista } \\
\text { 2000-2012 } \\
\end{array}$} & \multirow{2}{*}{$\begin{array}{c}\begin{array}{c}\text { Neoliberalismo } \\
\text { Priista } \\
\text { fase II }\end{array} \\
\text { Peña Nieto }\end{array}$} \\
\hline & Echeverría & Portillo & De la Madrid & Salinas & Zedillo & Fox & Calderón & \\
\hline & 1970-1976 & 1976-1982 & 1982-1988 & $\begin{array}{l}1988- \\
1994\end{array}$ & $\begin{array}{l}1994- \\
2000\end{array}$ & $\begin{array}{l}2000- \\
2006\end{array}$ & 2006-2012 & $2012-2016$ \\
\hline Minero & 2 & 0 & 3 & 4 & 3 & 3 & 3 & 2 \\
\hline Industrial & 19 & 60 & 112 & 220 & 174 & 115 & 76 & 109 \\
\hline Servicios & 50 & 29 & 131 & 220 & 232 & 127 & 156 & 148 \\
\hline Total & 71 & 89 & 246 & 444 & 409 & 245 & 235 & 259 \\
\hline
\end{tabular}

Fuente: elaboración propia, basada en los reportes bursátiles anuales de la BMV.

Como se puede observar, en la tabla $4 \mathrm{~b}$ se presentan los cuatro periodos históricos restantes, durante el periodo del populismo ${ }^{4}$ en los sexenios de Luis Echeverría Álvarez y José López Portillo, cae abruptamente la Bmv, este periodo ha sido llamado por la “Decena Trágica” Gollás (1994).

4 Comenta Aparicio (2010) que, durante el periodo del populismo, empieza a mermar la economía de México, principalmente por un crecimiento inflacionario, en 1971 se derrumba el sistema de Bretton Woods, al dejar de utilizar el patrón del oro por parte de Estados Unidos, lo que genera una importante devaluación del dólar. Además, se obtuvieron créditos en mercados internacionales y, con la política monetaria restrictiva del Tesoro de Estados Unidos, los intereses de la deuda se convirtieron en impagables, declarando una moratoria de la deuda hacia 1982. 
[...] la multiplicación del gasto público para atender demandas populares tuvo como consecuencia: a) un aumento en el déficit de cuenta corriente de la balanza de pagos (de 0.9 mil millones de dólares en 1971, cambio a 4.4 mil millones en 1975); b) la deuda externa creció de 6.7 mil millones de dólares en 1971, a 15.7 mil millones de dólares en 1975; y c) la tasa de inflación, de 3.4 por ciento en 1969, paso a 17 por ciento en 1975 (Gollás, 1994).

En el sexenio de López Portillo las expectativas de altos ingresos, producto de los descubrimientos petroleros, multiplicaron el gasto público, aumentaron la deuda externa y, para finales de 1981, el déficit total del sector público era del 14\% del Producto Interno Bruto (PIB). El resultado fue una devaluación del peso de 26 a 45 pesos por dólar. En agosto de 1982 el Gobierno Federal nacionalizó la banca privada, y en diciembre de ese año México declaró la moratoria al pago principal de su deuda externa. Esto provocó el cierre de flujos de crédito externo, el cese de las inversiones privada y pública, y una gran fuga de capitales (Ruíz, 1999).

El periodo del Neoliberalismo Priista ${ }^{5}$ fase i inicia en el sexenio de Miguel de la Madrid, lo que implica una reducción del gasto público y eliminación de subsidios y abrir la economía a la competencia externa. En 1985 se ingresa al GATT (Acuerdo General sobre Aranceles Aduaneros y Comercio) (Ruíz, 1999). Como resultado de esta política, se observa un repunte generalizado de la actividad industrial que produjo un superávit fiscal de entre 6 y 13.1 mil millones de dólares (Gollás, 1994) y se tradujo en ingreso de empresas para la вмv, que, si bien estaban lejos de los niveles previos de los sexenios de López Mateos y Díaz Ordaz, generaron una clara tendencia al alza.

Durante el sexenio del presidente Salinas de Gortari, el sector secundario tuvo un gran auge en las empresas bursátiles que no se ha vuelto a repetir a la fecha, así como el sector servicios. Durante este sexenio, hubo un cambio estructural en la política económica. Se

5 Explica Salazar (2004) que durante el neoliberalismo Priista fase i (1982-2000), México otorgó prioridad al capital financiero en sus políticas económicas, aceptando directrices del fmi y del bm. El déficit público fue señalado como una de las principales causas de la crisis económica, combatiéndola al centrarse en excluir la "pobreza extrema", según las palabras de la élite priista y el dominio de la tecnocracia neoliberal; aminorando radicalmente el aparato estatal (con la privatización), disminuyendo el gasto público en dos etapas centrales: 1) en el gobierno de Miguel de la Madrid donde se decreta el Pacto de Solidaridad Económica, 2) durante el gobierno de Salinas, donde se tuvo el objetivo de estabilizar los precios y se concretó la apertura comercial, con la firma del tlc; fijó el tipo de cambio; eliminó el déficit Fiscal, por medio de la privatización y la caída del gasto público y liberó la inversión extranjera directa. 
tomaron dos acciones destacadas: 1) se reprivatizaron los bancos en 1990, lo que propició un gran flujo de capitales y que las tasas de interés se redujeran y 2) se firmó el Tratado de libre comercio con Estados unidos y Canadá (TLCAN) en el año 1993 (Ruíz, 1999).

Aunque hubo grandes ingresos de divisas, derivados de esta política que se estimó en 154 mil millones de dólares, de enero a septiembre de 1991, desafortunadamente la existencia de un tipo de cambio fijo y la apertura comercial con el TLCAN favoreció a la competencia extranjera, que muchas empresas mexicanas fueron incapaces de enfrentar. Esto hizo que muchos productos importados fueran muy atractivos generando un impacto negativo en las reservas monetarias.

Cuando las reservas comenzaron a caer de una manera abrupta, se emitieron en México bonos de corto plazo (tesobonos) que garantizaban a los inversionistas su reembolso en dólares. En los últimos meses de 1994, la mayor parte de los bonos gubernamentales en manos privadas eran tesobonos (Ruíz, 1999, p. 9).

Aun cuando se generó una crisis económica y una devaluación muy importante del peso a finales del sexenio del presidente Zedillo, se mantuvo casi el mismo número de empresas que en el periodo del presidente Salinas.

Con respecto al Neoliberalismo Panista señala Gómez (2014), se trató de generar importantes cambios en materia de política social, ampliando el número de programas por medio de la Ley General de Desarrollo Social, con el propósito de obtener mayores derechos sociales. Pero la política resultó ser paralela a la seguridad social, y quedó sin erradicar la exclusión de la mayoría de los mexicanos de sus derechos sociales, reproduciendo tan solo una estrategia neoliberal. Se incrementó la pobreza por los niveles de ingresos, debido a la falta de estrategias de promoción de empleo y crecimiento económico, generando mayor desigualdad en el país, se puede observar en la tabla una disminución de las empresas que cotizaron en la bolsa.

Durante el periodo de Neoliberalismo Priista fase II, con el sexenio del presidente Peña, que para efectos de la investigación se consideraron solo cuatro años de su sexenio de 2012 a 2016. 
Menciona Ruíz (2017) que, al autorizarse la Reforma Energética, el presidente Peña Nieto afirmó que se podría alcanzar logros tan relevantes como los que se dieron con Lázaro Cárdenas (1934-1940). Sin embargo, hoy en día, la economía mexicana ha sido incapaz de encontrar mecanismos óptimos en la distribución de la riqueza, el potencial económico del país se ve obstaculizado por desafíos importantes como los altos niveles de pobreza, extensa informalidad, insuficiente aprovechamiento escolar, exclusión financiera, normas de derecho endebles y con altos niveles de corrupción y delincuencia.

\section{Discusión}

Como se puede observar en la tabla 5, la perdurabilidad de las 1663 empresas que cotizaron en la BMv durante el periodo de 1895 a 2016, el 51.53\% de las empresas desaparecen de la bolsa durante los primeros cinco años y el 30.31\% restante desaparece entre los 6 y 10 años, es decir que más del $80 \%$ de las empresas desaparecen de la BMv durante los primeros 10 años, y solo el $5.47 \%$ permaneció cotizando por más de 21 años, que corresponde a las 91 empresas analizadas utilizando la Teoría de Redes, que se presenta en la sección siguiente.

Por otra parte, se puede observar también que las empresas con mayor perdurabilidad son las del sector industrial, son las que han perdurado por más de 21 años cotizando en la BMV, y las empresas del sector servicios, son las que tienen mayor volatilidad en la bolsa ya que el $25.38 \%$ desapareció de la bolsa en los primeros cinco años y más del $40 \%$ desapareció en los primeros 10 años.

Tabla 5. Perdurabilidad de las empresas por sector económico de 1895 a 2016

\begin{tabular}{cccccccccc}
\hline & \multicolumn{2}{c}{ Minero } & \multicolumn{2}{c}{ Industrial } & \multicolumn{2}{c}{ Servicios } & \multicolumn{2}{c}{ Total } \\
\hline Perdurabilidad & $\begin{array}{c}\text { Número de } \\
\text { empresas }\end{array}$ & $\%$ & $\begin{array}{c}\text { Número de } \\
\text { empresas }\end{array}$ & $\%$ & $\begin{array}{c}\text { Número de } \\
\text { empresas }\end{array}$ & $\%$ & $\begin{array}{c}\text { Número de } \\
\text { empresas }\end{array}$ & $\%$ \\
\hline 1 a 5 & 159 & 9.56 & 276 & 16.60 & 422 & 25.38 & 857 & 51.53 \\
\hline 6 a 10 & 93 & 5.59 & 161 & 9.68 & 250 & 15.03 & 504 & 30.31 \\
\hline 11 a 20 & 21 & 1.26 & 104 & 6.25 & 86 & 5.17 & 211 & 12.69 \\
\hline 21 o más & 12 & 0.72 & 47 & 2.83 & 32 & 1.92 & 91 & 5.47 \\
\hline Total & 285 & 17.14 & 588 & 35.36 & 790 & 47.50 & 1,663 & 100 \\
\hline
\end{tabular}

Fuente: elaboración propia con base en BMV (2016). 
En la figura 1 se puede apreciar la participación global de cada uno de los sectores económicos que se fueron desarrollando por cada uno de los periodos presidenciales. Se presentan los datos de las empresas que cotizaron en la bmv durante el periodo de 1895 a 2016, la información se agrupó por sector económico y periodo presidencial durante los 121 años de vida de la bmv. Pudiendo observar claramente así que los periodos con mayor participación de empresas son el periodo del Porfiriato, el periodo del Desarrollo Estabilizador específicamente en los sexenios de los presidentes López Mateos y Gustavo Díaz Ordaz, también se observa una gran participación de empresas en el periodo del Neoliberalismo Priista fase i, especialmente en los sexenios de Salinas de Gortari y Zedillo.

Figura 1. Empresas por sector económico y periodo presidencial 1895-2016

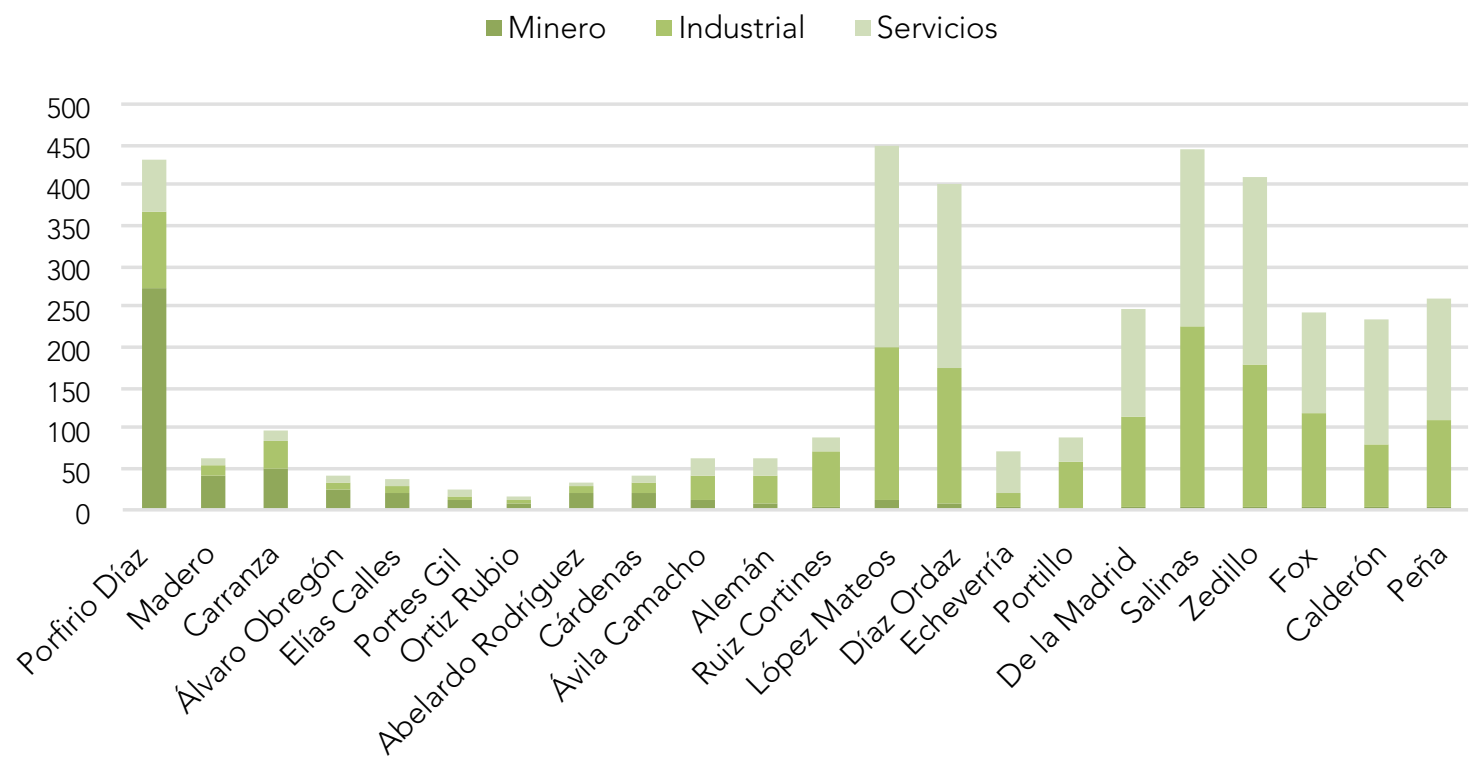

Fuente: elaboración propia, basada en los reportes bursátiles anuales de la BMV.

\subsection{Resultados del análisis con la Teoría de redes}

\section{Variables de centralidad estructural grado y cercanía}

Los resultados del análisis realizado por medio de la Teoría de Redes, de 91 empresas con más de 21 años cotizando en la Bмv 1895 a 2016, se conformó por 12 empresas del sector primario o minero, 47 empresas del sector secundario o industrial y 32 empresas del sector servicios. 
En la figura 2 se presentan los tres sectores analizados, la variable grado permite identificar a los sectores con mayor perdurabilidad, pudiendo observar con esto que el nodo de mayor tamaño corresponde a las empresas del sector industrial, es decir, que son las que tienen mayor participación, estas empresas son las que han tenido mayor perdurabilidad en la BMV, cotizando por más de 50 años. En segundo lugar, se ubican las empresas del sector servicios; la muestra seleccionada incluye principalmente empresas bancarias, porque son las que han cotizado por más de 21 años, aunque en los últimos años el sector servicios es el que tiene mayor participación en la bolsa, no así la mayor perdurabilidad, ya que el sector servicios es el que presenta mayor volatilidad en la bolsa; el tercer lugar lo ocupan las empresas del sector primario o minero, las cuales cotizaron por más de 50 años en la BMV y, sin embargo, para 2016 habían desaparecido, debido a que sus actividades pasaron al sector industrial.

Figura 2. Empresas con más de 20 años de cotizar en la bmv por sectores económicos

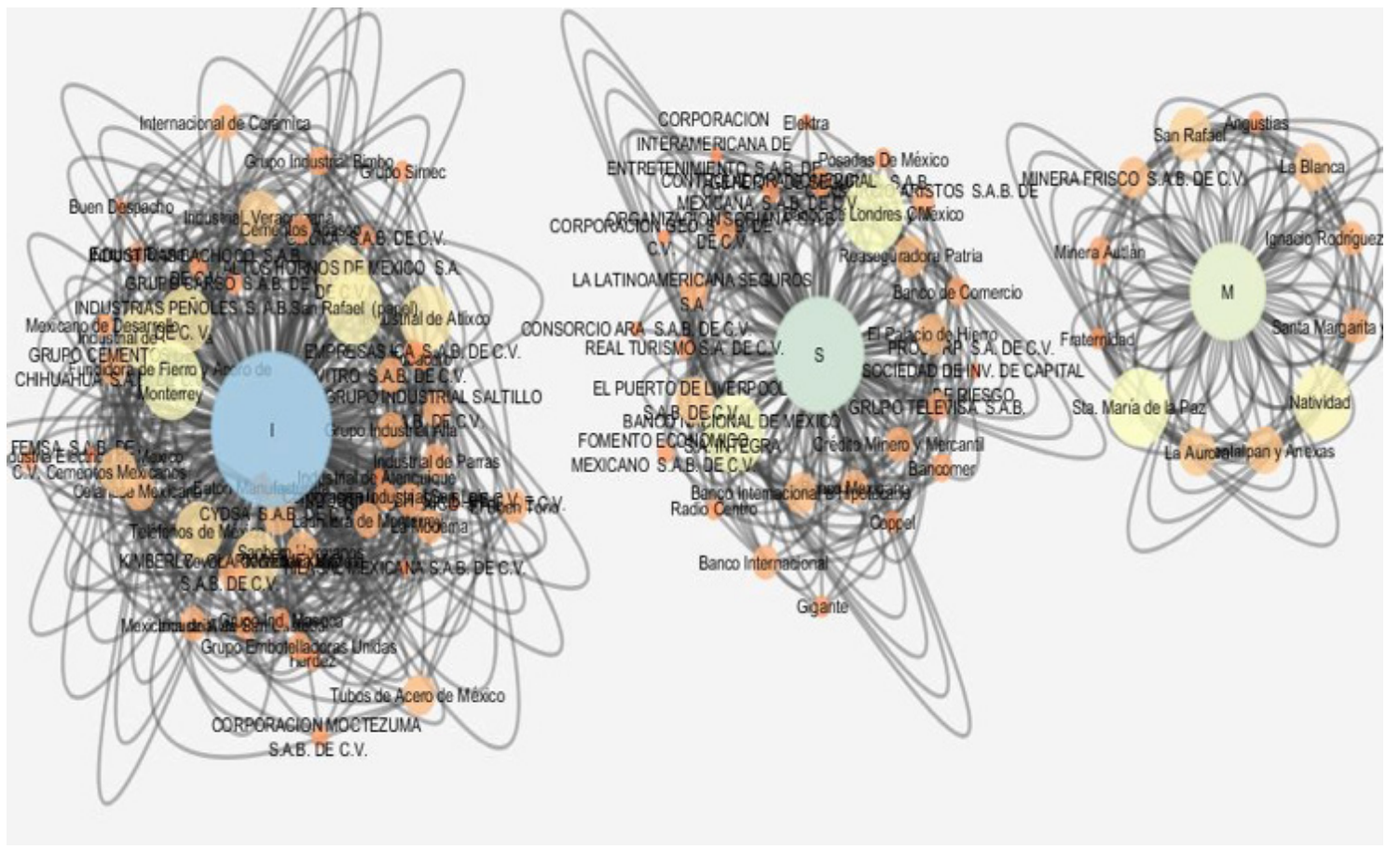

Fuente: elaboración propia, basada en los reportes bursátiles anuales de la BMV.

En la tabla 6 se presenta la información de las empresas con mayor perdurabilidad en el periodo analizado, la variable grado indica el número de periodos presidenciales en el que cotizaron las empresas en la BMv, la variable cercanía indica la injerencia de las empresas 
en los diferentes periodos presidenciales, es decir la cercanía de las empresas con los presidentes en turno. Se comprueba que existe correlación positiva entre las variables grado y cercanía, a mayor grado mayor cercanía, por ejemplo el Banco Nacional de México, S.A. cotizó durante 75 años en 18 periodos presidenciales; la variable cercanía tiene un índice alto de 0.53 indica la influencia de Banamex en los diferentes periodos presidenciales, un escenario que podría explicar esta situación es que las empresas ligadas a los presidentes en turno contaban con apoyos gubernamentales.

Tabla 6. Variables de centralidad de las empresas con mayor perdurabilidad en la BMV

\begin{tabular}{|c|c|c|c|c|}
\hline Empresas & $\begin{array}{c}\text { Sector } \\
\text { económico }\end{array}$ & $\begin{array}{c}\text { Años cotizados } \\
\text { en BMV }\end{array}$ & Grado & Cercanía \\
\hline Banco Nacional de México S.A. Integra & $\mathrm{S}$ & 75 & 18 & 0.53 \\
\hline Sta. María de la Paz & M & 57 & 14 & 0.38 \\
\hline Banco de Londres y México & $\mathrm{S}$ & 52 & 14 & 0.38 \\
\hline Fundidora de Fierro y Acero de Monterrey & I & 61 & 14 & 0.38 \\
\hline Natividad & M & 54 & 13 & 0.37 \\
\hline San Rafael (papel) & I & 56 & 13 & 0.38 \\
\hline Altos Hornos de México S.A. de C.V. & I & 46 & 12 & 0.50 \\
\hline Industrias Peñoles S.A.B. de C. V. & I & 53 & 12 & 0.50 \\
\hline Industrial de Atlixco & I & 43 & 12 & 0.37 \\
\hline Industrial de Orizaba & I & 56 & 12 & 0.37 \\
\hline Teléfonos de México & $\mathrm{S}$ & 51 & 11 & 0.47 \\
\hline Cervecería Moctezuma & I & 40 & 11 & 0.50 \\
\hline San Rafael & M & 40 & 10 & 0.32 \\
\hline Industrial Veracruzana & I & 32 & 10 & 0.36 \\
\hline El Puerto de Liverpool S.A.B. de C.V. & $\mathrm{S}$ & 40 & 9 & 0.46 \\
\hline Chontalpan y Anexas & M & 27 & 9 & 0.31 \\
\hline La Aurora & M & 31 & 9 & 0.36 \\
\hline La Blanca & M & 40 & 9 & 0.32 \\
\hline Cementos Mexicanos & I & 36 & 9 & 0.47 \\
\hline Minera Frisco S.A.B. de C.V. & M & 24 & 8 & 0.45 \\
\hline Sanborns Hermanos & S & 34 & 8 & 0.46 \\
\hline Celanese Mexicana & I & 35 & 8 & 0.46 \\
\hline Banco Internacional e Hipotecario & $\mathrm{S}$ & 25 & 8 & 0.33 \\
\hline Reaseguradora Patria & $\mathrm{S}$ & 28 & 8 & 0.45 \\
\hline El Palacio de Hierro & S & 38 & 8 & 0.45 \\
\hline Cydsa S.A.B. de C.V. & I & 32 & 8 & 0.41 \\
\hline Tubos de Acero de México & I & 31 & 8 & 0.46 \\
\hline El Buen Tono & I & 28 & 7 & 0.36 \\
\hline Mexicana de Aviación & S & 28 & 7 & 0.45 \\
\hline
\end{tabular}

Fuente: elaboración propia, basada en los reportes bursátiles anuales de la BMV. 
Para efectos de dar mayor claridad en la información, en el figura 3 se presenta a las 47 empresas del sector industrial que históricamente han tenido mayor perdurabilidad en la BMV de 1895 a 2016, los nodos de mayor tamaño corresponden a las empresas con mayor grado, que cotizaron por más de 50 años, así como a los presidentes con mayor número de empresas en sus periodos presidenciales: por ejemplo, Fundidora de Fierro y Acero de Monterrey con 61 años de cotización, con un grado de 14, es el número de periodos presidenciales en los que cotizó en la BMv y cercanía de 0.39 es un índice medio, lo cual significa que la empresa estuvo cercana a 14 presidentes. También se observa en la parte central de la figura a los presidentes con mayor número de empresas en sus periodos presidenciales fueron Zedillo, Salinas, Fox, y Calderón.

Figura 3. Empresas del sector industrial con mayor perdurabilidad de 1895 a 2016

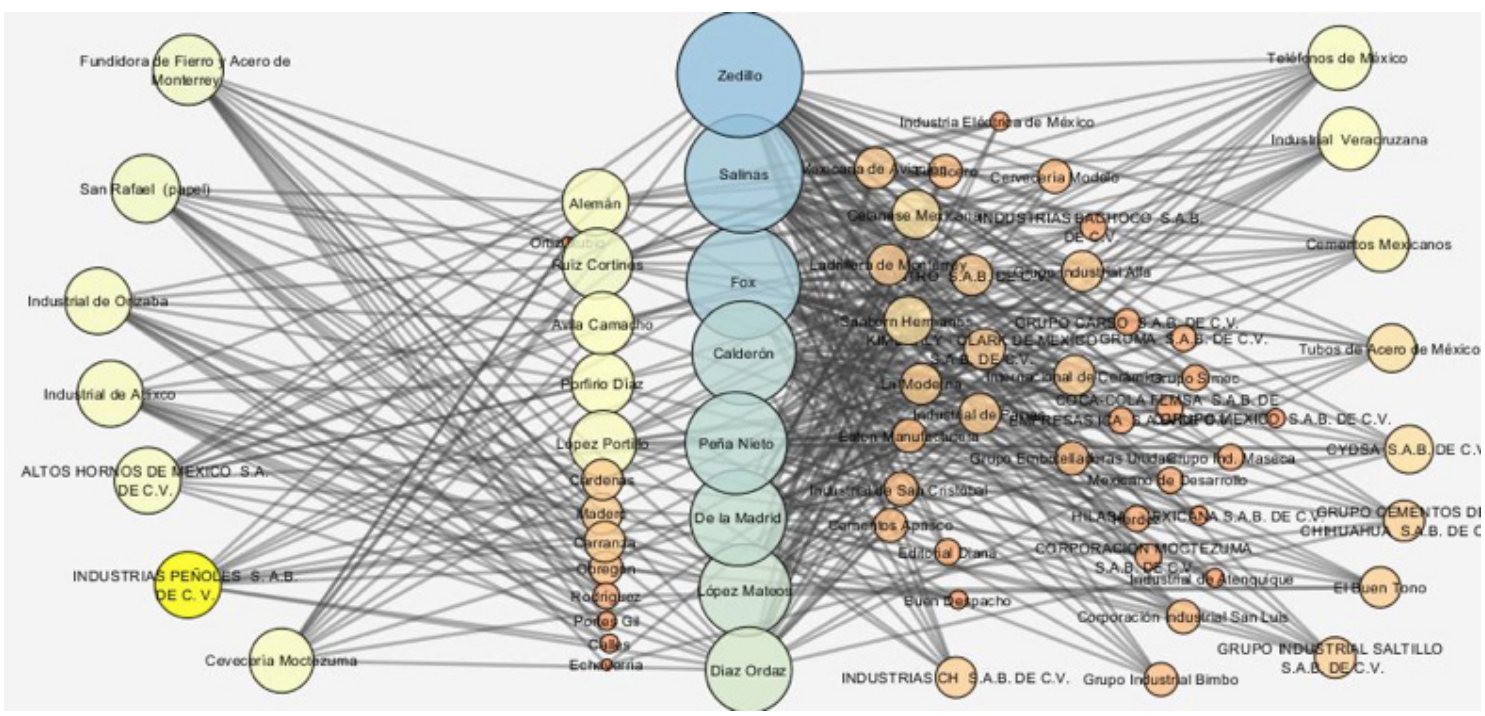

Fuente: elaboración propia, basada en los reportes bursátiles anuales de la BMV.

En la figura 4 se presenta al sector servicios con 32 empresas, es el sector con mayor volatilidad en la BMv, en este sector prevalecen las empresas bancarias, por el tamaño de los nodos se puede observar a las empresas bancarias con mayor grado, así como a los presidentes con mayor número de empresas en sus periodos presidenciales. En primer lugar, se ubica Banco Nacional de México con 75 años de cotización en 18 periodos presidenciales, es la empresa con mayor perdurabilidad en la BMv en los 121 años analizados; en segundo lugar, Banco de Londres y México con 52 años de cotizaciones en 14 periodos 
presidenciales; en tercer lugar, Puerto de Liverpool con 40 años en 9 periodo presidenciales y, en cuarto lugar, el Banco Internacional e Hipotecario con 25 años en 8 periodos presidenciales. Por otra parte, los presidentes con mayor grado se ubican al centro de la figura, encabezando la lista Zedillo, Calderón y Fox.

Figura 4. Empresas del sector servicios con mayor perdurabilidad en la BMV 1895 a 2016

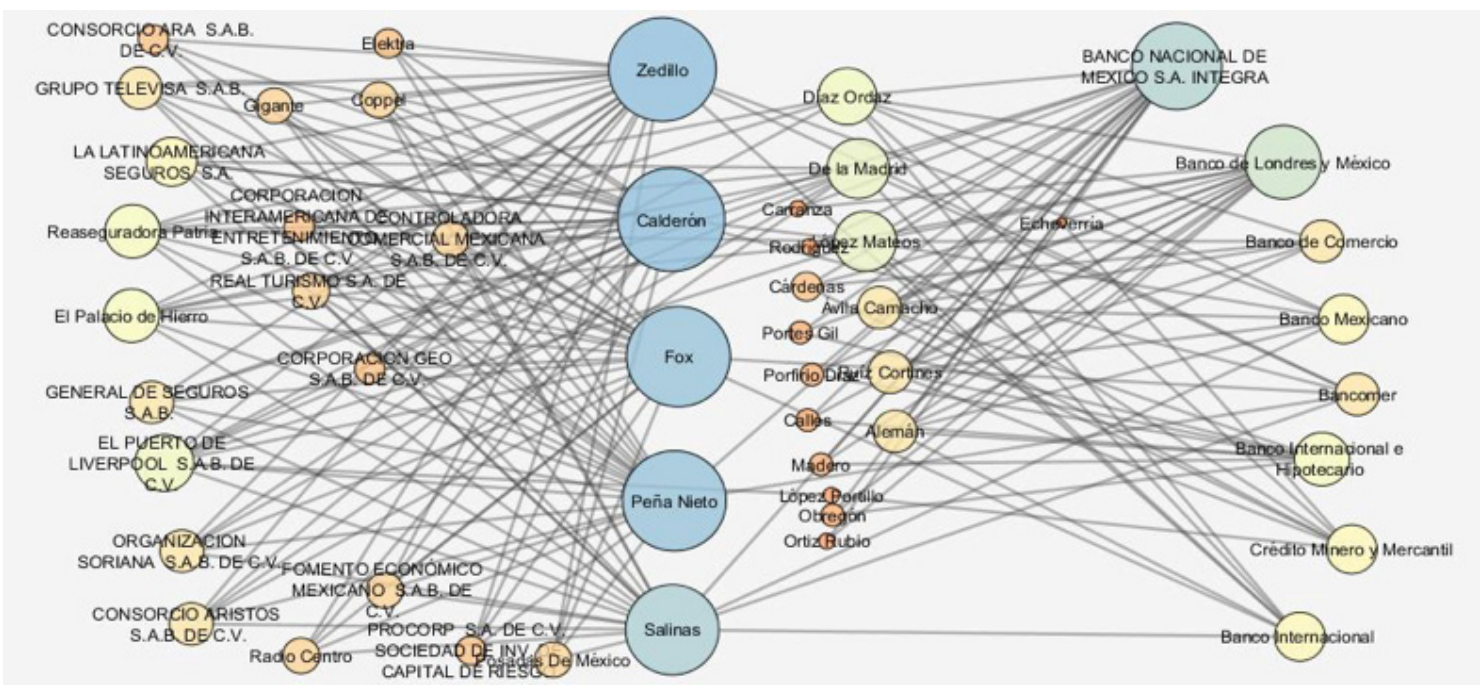

Fuente: elaboración propia, basada en los reportes bursátiles anuales de la BMv.

En la figura 5 se presenta el análisis de las 12 empresas mineras con más de 20 años de perdurabilidad en la BMv de 1895 a 2016, la variable grado permite identificar por el tamaño del nodo a las empresas con mayor perdurabilidad, así como a los presidentes que tuvieron mayor número de empresas en sus periodos. Las empresas con mayor grado son Sta. María de la Paz con 57 años de cotizar en la BMV, con un grado de 14 y cercanía de 0.38 que significa que la empresa participó en 14 periodos presidenciales con una cercanía alta; la empresa Natividad con 54 años con grado de 13 y cercanía de 0.37; San Rafael con grado de 10 y cercanía 0.32 y La Blanca con grado de 9 y cercanía de 0.32 , también se puede apreciar que el presidente con mayor influencia en el sector fue Porfirio Díaz, como se puede apreciar en la figura 5. 
Figura 5. Empresas mineras con mayor perdurabilidad en la BMV de 1895 a 2016

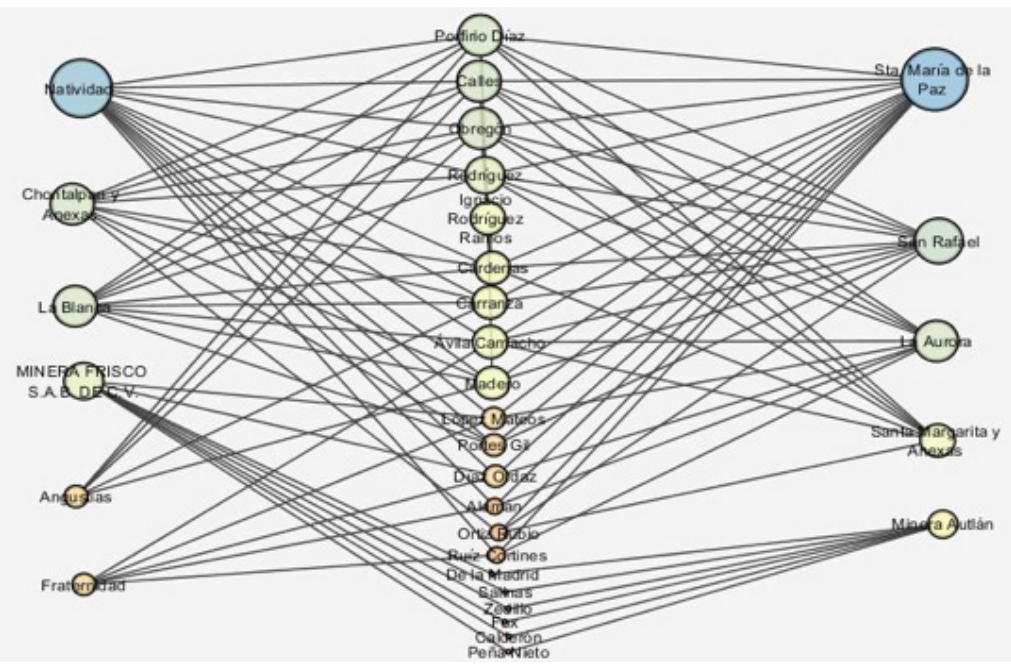

Fuente: elaboración propia, basada en los reportes bursátiles anuales de la BMV.

\section{Conclusiones}

Los resultados del análisis sobre la perdurabilidad de las empresas en la BMv, durante el periodo de 1895 a 2016, permite concluir que el sector primario predominó a finales del siglo xIX con la minería y durante el siglo xx sobresalió el sector secundario con el desarrollo de la industria y, finalmente, la tendencia para el siglo xxI, es cada vez más destacado el sector servicios. El sector minero actualmente ya no es representativo, debido a que inicialmente fue el de extracción de minerales. Actualmente, al realizar la transformación del mineral en producto terminado, se genera un cambio en los procesos y de acuerdo con las normas de clasificación oficiales del TLCN, dicha acción genera también un cambio al sector económico secundario.

Se identificaron tres periodos claros de perdurabilidad de empresas en la BMv: el primero del presidente Porfirio Díaz que ha sido el más largo y prolífico de la historia, estuvo concentrado en el sector primario por la preeminencia de las minas. El segundo es el periodo del Desarrollo Estabilizador que inicia con el gobierno del presidente Cárdenas y la industrialización impulsada por el presidente Ávila Camacho y continuado por Alemán y Ruiz Cortines, teniendo el mayor repunte en los sexenios de los presidentes López Mateos y Díaz Ordaz. El tercero se inicia con el periodo del Neoliberalismo Priista fase i, en el 
sexenio de Miguel de la Madrid, tiene su arranque en el periodo del presidente Salinas que fue continuado pese a la crisis final de su sexenio por el presidente Zedillo.

Los resultados obtenidos permiten comprobar que el periodo del Porfiriato y el llamado desarrollo estabilizador, así como el ciclo del modelo neoliberal Priista fase i, tuvieron una asociación positiva con la perdurabilidad empresarial en la BMv.

Por otra parte, los datos generales indican que la perdurabilidad de las empresas en la BMv es muy baja, el $51.53 \%$ no pasa de los 5 años, el $30.31 \%$ sobrevive entre 6 y 10 años, el $12.69 \%$ entre 11 y 20 años y solo el 5.47\% de las empresas ha perdurado por más de 21 años. También se comprueba que las empresas del sector industrial son las que presentaron mayor perdurabilidad en la BMv, aunque no son las de mayor participación y las empresas del sector servicios son las que presentan mayor volatilidad, aunque actualmente son las que tienen mayor participación y las empresas mineras desaparecieron de la BMv. Las empresas del sector terciario o de servicios confirman tener actualmente mayor participación en la BMv, el $25.38 \%$ de estas solo cotizan por periodos entre de 1 a 5 años, es decir que tienen mayor volatilidad.

El análisis con la Teoría de Redes complejas permite concluir y visualizar claramente la información de empresas (Chamarro, Domínguez \& García, 2017), con mayor perdurabilidad del periodo analizado (1895-2016), el 41\% de empresas que cotizaron durante más de 21 años en la Bmv había desaparecido para el año 2016, del 59\% restante, 32\% corresponde a empresas del sector industrial, 25\% al sector servicios y finalmente sólo el $2 \%$ al sector minero. También se pudo observar que, a pesar de que las empresas del sector secundario o industrial es inferior en número de empresas bursátiles, mostraron alcanzar un mayor grado de perdurabilidad, lo que demuestra que están cotizando activamente en BMV, identificando empresas que tienen más de 50 años activas en el mercado accionario Dinca, Dinca y Pal (2014).

Con respecto a las dos variables de centralidad analizadas con el software CYTOSCAPE, grado y cercanía, los resultados permiten concluir que las empresas con mayor grado tienen índices altos en la variable cercanía, esto significa que las empresas con mayor número de años de cotización en la BMv mantuvieron mayor injerencia en los periodos presidenciales, se comprueba que existe correlación positiva entre las variables grado y cercanía, a mayor 
grado mayor cercanía, un escenario que podría explicar esta situación es la relación de las empresas con los presidentes en turno, las cuales contaban con apoyos gubernamentales. También se comprueba que el sector industrial ha tenido mayor perdurabilidad en la BMv y que el sector servicios presenta ciclos de vida más cortos.

Las variables de centralidad grado y cercanía permiten comprobar cuantitativamente que los presidentes con mayor número de empresas en sus periodos presidenciales de acuerdo con la clasificación por los tres sectores fueron para el sector primario, el presidente Porfirio Díaz y para el sector secundario o industrial, los presidentes Zedillo y Salinas y Fox y para el sector terciario o de servicios, fueron los presidentes Zedillo, Calderón y Fox.

Los resultados muestran con mayor frecuencia, que los sectores de servicios serán los que tendrán un mayor crecimiento por medio de servicios más especializados y con mayor sofisticación y calidad y, adicionalmente, se expresa que cuando un gobierno apoya a las empresas de los distintos sectores económicos, para que impulse el desarrollo de más empresas bursátiles activas, será un referente de perdurabilidad en la BMv, transformándose en el tiempo en sectores de mayor importancia de acuerdo con cada una de las épocas de desarrollo económico donde iniciaron.

\section{Referencias}

Aparicio, C. A. (2010). Economía mexicana 1919-2010: balance de un siglo. Ciudad de México: Universidad Autónoma de México. Recuperado de http://www.economia.unam.mx/profesores/aaparicio/Econom\%C3\%ADa.pdf

BMV (1994). 100 años de la Bolsa Mexicana de Valores 1894-1994. México.: BMV.

Cárdenas, M., Rivas, L. A., Ramírez, F. \& Simón, N. (2015). Análisis de la estructura de una red conocimiento en México. Revista de Ciencias Sociales, xxi(4), 521-537. Recuperado de http://www.redalyc.org/articulo.oa?id=28043815006> ISSN 1315-9518

Castro, J. A., Chávez, M. F. \& Rodríguez, C. E. (2016). La depreciación del peso mexicano durante 2012-2015 y su efecto en el Índice de Precios y Cotizaciones de la Bolsa Mexicana de Valores. Economía Informa, 397(10), 105-121. 
Chamorro, G., Domínguez, B. \& García, M. (2017). El financiamiento de la banca comercial y el mercado de capitales. Panorama económico, 12(24), 91-114. https://doi.org/10.29201/ pe-ipn.v12i24.164

Colegio de México (2003). México, crecimiento con desigualdad y pobreza: (de la sustitución de importaciones a los tratados de libre comercio con quien se deje). Ciudad de México: COLMEX. Recuperado de https://cee.colmex.mx/documentos/documentos-de-trabajo/2003/dt20033.pdf

Díaz, G. \& García, G. (2017). Identificación de condiciones de auto-organización en los mercados financieros bursátiles de los países pertenecientes al MILA: Una mirada desde los Sistemas Complejos Adaptativos. Bogotá: Universidad de la Salle. Recuperado de http:// repository.lasalle.edu.co/bitstream/handle/10185/24999/63101165_2017.pdf?sequence $=1 \&$ isAllowed $=y$

Dinca, G., Dinca, M. S. \& Pal, A. R. (2014). The importance of the dsiciminant analysis for the evolution in prices. Bulletin of the Transilvania University of Brasov, 7(2), 197-206. Recuperado de http://webbut.unitbv.ro/BU2014/Series\%20V/BULETIN\%20V/IV-04_ DINCA.pdf

Economía (2016). Sectores económicos. La gran enciclopedia de economía. Recuperado de http://www.economia48.com/spa/d/sectores-economicos/sectores-economicos.htm.

Gollás, M. (1994). México 1944: Una economía sin inflación,sin igualdad y sin crecimiento. México: El Colegio de México.

Gómez, K. R. (2014). ¿Neo o post-neoliberalismo en la política social de México? Una comparación entre las estrategias de política seguidas durante la década del 2000 y la ¿nueva? estrategia del sexenio priísta (2012-2018). Revista Mexicana de Análisis Político y Administración Pública, 3(1), 179-202. Recuperado de https://scholar.google.com.mx/scholar?hl=es\&as_ $\mathrm{sdt}=0 \% 2 \mathrm{C} 5 \& \mathrm{q}=\mathrm{NEOLIBERALISMO}++\mathrm{EN}+\mathrm{MEXICO}+\mathrm{DE}+2000+\mathrm{AL}+2012 \& \mathrm{btnG}=$

Huerta, E. (2016). La bolsa mexicana no corresponde al tamaño de su economia. El Economista. Recuperado de https://www.eleconomista.com.mx/mercados/La-BMV-no-correspondecon-el-tamano-de-la-economia-20160629-0101.html

INEGI (2013). Sistema de Clasifiación Industrial de América del Norte. Recuperado de http:// internet.contenidos.inegi.org.mx/contenidos/Productos/prod_serv/contenidos/espanol/ bvinegi/productos/clasificadores/SCIAN/SCIAN_2013/702825051693.pdf.

INEGI (2018). Sectores económicos. INEGI. Recuperado de http://www.beta.inegi.org.mx/ temas/productividadsec/.

Islas, V. M. (2017). Genealogía de Grupo México. Ciudad de México: unam. Recuperado de http://let.iiec.unam.mx/sites/let.iiec.unam.mx/files/boletin4FINALimpresion.pdf\#page=23 
Lancheros, B. (2017). Análisis del proceso de integración del mercado latinoamericano (MILA) desde el 2011 al 2016. Bogotá: Corporación Unieversitaria Iberoamericana. Recuperado de http://repositorio.jbb.gov.co/bitstream/001/414/1/An\%C3\%A1lisis\%20del\%20proceso\%20 de\%20integraci\%C3\%B3n\%20del\%20mercado\%20latinoamericano\%20\%28MILA\%29\%20 desde\%20el\%202011\%20al\%202016.pdf

Lara, P. (2013). Breve historia de la Industrialización en México. Recuperado de https://pedrolarav.com/2013/11/16/breve-historia-de-la-industrializacion-en-mexico/

Montes, P. J. (2017). Marco tributario en la adquisición de una compañía. Comparación entre el método de compra de activos y la compra de acciones. El caso de una empresa privada manufacturera mexicana en 2015. San Luis Potosí: Universidad Autónoma de San Luis Potosí. Recuperado de http://ninive.uaslp.mx/jspui/bitstream/i/4160/1/Tesis\%20 Alberto\%20Montes\%20Pe\%CC\%81rez.pdf

Moreno, I. S. (2016). The Blockchains Technology Revolution of and its Impact on the Economic Sectors. Bogota: CEDE.

Moreno, S., Rodero, O. \& Moreno, T. (2018). Estructura de capital de las empresas pertenecientes al mila en el periodo 2008-2016. Bogotá: Universidad de La Salle. Recuperado de http://repository.lasalle.edu.co/bitstream/handle/10185/25012/63122097_2018.pdf?sequence $=1 \&$ isAllowed $=\mathrm{y}$

Moreno-Lázaro, J. (2015). The stock exchange, the state and economic development in mexico, 1932-1975. Revista de Historia Economica, 33(2), 321-350. https://doi.org/10.1017/ S021261091500018X

Moya, G. A. (2007). Historia, arquitectura y nación bajo el régimen de Porfirio Díaz. Ciudad de México 1876-1910. Revista de Ciencias Sociales (Cr), 3(117-118), 159-182. Recuperado de http://www.redalyc.org/html/153/15311812/

Neal, L. \& Davis, L. (2006). The evolution of the structure and performance of the london stock exchange in the first global financial market, 1812-1914. European Review of Economic History, 1O(3), 273-300. https://doi.org/10.1017/S1361491606001766

OCDE (2017). Estudios economicos de la OCDE vision. MÉXICO: OCDE. Recuperado de https://www.oecd.org/.../mexico

ONU (2016). El progreso de las mujeres en el mundo 2015-2016. Transformar las economías para realizar los derechos. Revista Estudos Feministas, 24(2), 589-614.

Paz, S. (2006). La Política Económica de la Revolución Mexicana 1911-1924(1A. ed.). Ciudad de México: Fondo Editorial fca. Recuperado de https://books.google.com.mx/books?id=2Q58XQB3F30C\&pg=PA124\&dq=PRESIDENTES+DURANTE+EL+PERIODO+REVOLUCIONARIO++DE+1911-1924\&hl=es\&sa=X\&ved=0ahUKEwi68aS_tcDdAhUFCawKHfnf- 
BKcQ6AEIJzAA ${ }^{*} \mathrm{v}=$ onepage\&q=PRESIDENTES\%20DURANTE\%20EL\%20PERIODO $\% 20$ REVOLUCIONARIO\%20\%20DE\%20

Pérez-Fernández, R. (2010). Teoría y Práctica de la Bolsa. Todo lo que debe saber el inversor sobre mercados financieros. México: Eds. Díaz de Santos.

Ramírez, A. M. (2013). El maximato: mito y realidad del poder político en México. Vivat Academia (125), 52-67. Recuperado de http://www.redalyc.org/pdf/5257/525752944005.pdf

Ren, F. \& Zhou, W. (2014). Dynamic evolution of cross-correlations in the chinese stock market. Plos One, 9(5), e97711. Doi:10.1371/journal.pone.0097711

Ruíz, C. (1999). La economía y las modalidades de la urbanización en México: 1940-1990. Economía Sociedad y Territorio, ii(5), 1-24. Doi:org/10.22136/est001999456

Ruiz, R. V. (2017). Las «Fuerzas Ocultas» del desarrollo capitalista en México y el contexto Intrenacional. Entretextos, 9(27), 1-15. Recuperado de http://entretextos.leon.uia.mx/ num/27/labor-de-punto/PDF/ENTRETEXTOS-27-A4.pdf

Salazar, F. (2004). Globalización y política neoliberal en México. El cotidiano, 20(126), 1-12. Recuperado de http://www.redalyc.org/pdf/325/32512604.pdf

San Martín, R., Durán, V. \& Durán, E. (2017). Relación entre Concentración de Propiedad Familiar y Discrecionalidad directiva: Evidencia del caso de México. Revista Mexicana de Economía y Finanzas Nueva Época REMEF, 9(1), 1-17. http://dx.doi.org/10.21919/ remef.v9i1.53.

San Martin-Reyna, J. M. \& Duran- Escalada, J. A. (2012). The relationship among family business, corporate governance and firm performance: Evidence from the mexican stock exchange. Journal of Family Business Strategy, 3(2), 106-117. https://doi.org/10.1016/j.jfbs.20

Soane, J. F. \& Laxe, F. (2003). Economía del transporte marítimo. España: Instituto Universitario de Estudios Martítimos. Recuperado de https://books.google.com.mx/books?hl=es\&lr=\&i$\mathrm{d}=$ SfSOaU_CSrkC\&oi=fnd\&pg=PA9\&ots=eu6Ch_efUX\&sig=m5fNYkBITG6PudDKFx7hEMnEGfc $^{\#} \mathbf{v}=$ onepage $\& q \& \mathrm{f}=$ false.

Wang, G., Han, F., Sun, B. \& Xie, C. (2012). Similarity measure and topology evolution of foreign exchange markets using dynamic time warping method: Evidence from minimal spanning tree. Physica A: Statistical Mechanics and its Applications, 391(16), 4136-4146.

Wang, G., Xie, C. \& Chen, S. (2017). Multiscale correlation networks analysis of the US stock market: A wavelet analysis. Journal of Economic Interaction and Coordination, 12(3), 561-594. https://doi.org/10.1007/s11403-016-0176-x

Wang, G., Xie, C. \& Stanley, H. E. (2018). Correlation structure and evolution of world stock markets: Evidence from pearson and partial correlation-based networks. Computational Economics, 3, 607-635. https://doi.org/10.1007/s10614-016-9627-7 
WFE (2017). The World Federation of Exchanges publishes report into SME financing E equity markets. Recuperado de https://www.world-exchanges.org/news/articles/world-federation-of-exchanges-publishes-report-into-sme-financing-equity-markets

Zuleta, H. \& Gómez, L. B. (2016). Conflicto, Sectores, Regiones y Crecimiento. Documento CEDE, (29). 